\title{
ARTICLE
}

Received 11 Feb 2015 | Accepted 29 Jan 2016 | Published 21 Mar $2016 \quad$ DOl: 10.1038/ncomms10886 OPEN

\section{Morphodynamics of submarine channel inception revealed by new experimental approach}

\author{
Jan de Leeuw ${ }^{1}$, Joris T. Eggenhuisen ${ }^{1} \&$ Matthieu J.B. Cartigny ${ }^{2}$
}

Submarine channels are ubiquitous on the seafloor and their inception and evolution is a result of dynamic interaction between turbidity currents and the evolving seafloor. However, the morphodynamic links between channel inception and flow dynamics have not yet been monitored in experiments and only in one instance on the modern seafloor. Previous experimental flows did not show channel inception, because flow conditions were not appropriately scaled to sustain suspended sediment transport. Here we introduce and apply new scaling constraints for similarity between natural and experimental turbidity currents. The scaled currents initiate a leveed channel from an initially featureless slope. Channelization commences with deposition of levees in some slope segments and erosion of a conduit in other segments. Channel relief and flow confinement increase progressively during subsequent flows. This morphodynamic evolution determines the architecture of submarine channel deposits in the stratigraphic record and efficiency of sediment bypass to the basin floor.

\footnotetext{
${ }^{1}$ Faculty of Geosciences, Utrecht University, PO Box 80021, 3508TA Utrecht, The Netherlands. ${ }^{2}$ National Oceanography Centre, European Way, Southampton, Hampshire SO14 3ZH, UK. Correspondence and requests for materials should be addressed to J.d.L. (email: J.deleeuw@uu.nl).
} 
E xtensive channelized seascapes have been revealed by seafloor surveys ${ }^{1-4}$. The channels are characterized by a continuous thalweg along which sediment-laden turbidity flows dominantly bypass sediment ${ }^{5}$. Submarine channels can be up to several kilometres wide and hundreds of kilometres long, and provide the transport pathways for large quantities of sediment, nutrients and carbon into the deeps of the world's ocean ${ }^{1,6}$, where the material is collected in basin-floor fans that form the largest sediment accumulations on the planet.

Seafloor and outcrop evidence demonstrates that channels are associated with erosion into underlying deposits ${ }^{7}$ and aggradation of deposits in levees, channel fills and splays ${ }^{8}$. Fundamentally, different causalities have been suggested in the spatial and temporal relations between erosive and depositional changes to the submarine landscape. Some studies 9,10 envision an evolution where 'only after an initial erosional phase and channel establishment are turbidity currents able to construct aggrading levees'9. This contrasts with suggestions that genetically linked precursor lobe morphologies may form an initial depositional template for subsequent channel incision ${ }^{8,11-13}$, and that channels may be entirely depositional both outside and inside the confining conduit ${ }^{7,14}$.

Subsurface and outcrop observations on channel morphology and channel deposits are static. Similarly, the presently available direct observations of active submarine channels ${ }^{4,15-18}$ do not span enough time to study morphodynamics of channel inception and evolution. In recent times, the extension of a submarine channel has been monitored in a quickly evolving system ${ }^{19}$. However, the data set did not provide direct information about the flow conditions during this morphological evolution. Therefore, modelling studies remain important in the investigation of the morphodynamic interplay between channel form and turbidity currents.

A limited number of experiments successfully produced subaqueous channels using a saline flow over a mobile substrate $^{20-22}$. However, these flows could not produce depositional morphologies, as there was no suspended sediment load, which is vital for levee formation ${ }^{22}$. Therefore, these experiments provide limited insight into contributions of deposition and erosion during channel inception. Rowland et al. ${ }^{23}$ reviewed the full range of published numerical and physical experiments that have tried to achieve self-channelization ${ }^{24-26}$ by sediment-laden flows and concluded that channelization was not achieved in any of the cases.

We present experiments that for the first time capture selfchannelization by turbidity currents. This was achieved by scaling sediment suspension in the experimental turbidity currents to the real world systems. This new scaling approach is called Shields scaling and focuses on two scaling parameters that regulate sediment suspension: (1) the Shields parameter and (2) a Reynolds scale of the sediment grains. The observed morphodynamic channel evolution establishes that channel inception can either commence with deposition of confining morphology by turbidity currents or erosion of a channel conduit. Thus, channel inception is not exclusively possible following erosion.

\section{Results}

Scaling approach. Classical turbidity current experiments ${ }^{23,24,27-35}$ have focused on two non-dimensional scaling characterizations of the fluid flow: the Froude number $(F r)$, which is the ratio between momentum and gravitational forces of the flow, and the Reynolds number $(R e)$, characterizing the ratio between the momentum and the viscous forces that determine the turbulent state of the flow. As it is not possible to keep both $F r$ and Re equal to the natural analogues while scaling down flow size, it is common to keep the $\mathrm{Fr}$ similar to natural values and to only require a $R e$ above the laminar-turbulent threshold ${ }^{36,37}$. This Froude scaling approach has proven to be valuable in understanding the flow dynamics of turbidity currents but it does not guarantee that flows are able to transport sediment in suspension.

Many Froude-scaled experiments displayed rapid sediment depletion and were therefore limited in clarifying patterns of deposition and erosion. Depletive flows rapidly lose their complete sediment load, because they do not have enough turbulent mixing to compensate for settling of sediment from suspension. To predict whether currents are able to entrain and transport sediment in suspension, it is important to consider the force ratios acting on the sediment grains. This leads to two additional constraints: the Shields parameter, being the ratio between the turbulent shear, as expressed by the shear velocity, and the gravity-induced settling ${ }^{38}$; and the particle $R e$, which is the ratio of grain size to the boundary layer thickness ${ }^{39}$. The former is more commonly quoted in turbidity current studies ${ }^{29}$ as the ratio between the shear velocity $\left(u^{*}\right)$ and the settling velocity $\left(u_{\mathrm{s}}\right)$, but is here expressed as the Shields parameter. The latter is a Reynolds scale with significance for particle suspension near the bed. It describes the roughness of the sediment surface, which determines whether flow at the boundary is smooth and dominated by viscous forces, or rough and dominated by turbulent forces and shedding of turbulent eddies from particles at the bed surface ${ }^{40}$. If the boundary is smooth, a thin layer of laminar flow protects the bed and grains that settle into this near-bed boundary layer will no longer interact with suspending turbulent structures and are likely to remain deposited. In the transitionally rough regime, there is interaction of turbulent eddies with the bed but viscous forces also have a significant role. As experiments on channel inception are dependent on realistic turbulence-sediment interactions, both in the boundary layer and in suspension, it follows that such Shields scaling constrains must be satisfied.

The Shields scaling approach mirrors Froude scaling of the flow dynamics in the sense that one scale, namely the ratio of turbulent forces and gravity forces acting on the particle (the Shields parameter), is kept equal to real world values, whereas the other scale (the Reynolds particle scale) is relaxed, as long as rough to transitionally rough boundary layer conditions are maintained, to keep a realistic turbulent near-bed regime and aid sediment pick-up into suspension. These two scales form the axes of the classic Shields mobility diagram (Fig. 1), which enables a comparison between the present experiments, natural turbidity current conditions and previous experimental studies.

Comparison with natural currents and previous experiments. In situ measurements of turbidity currents in the Monterey Canyon ${ }^{15,16}$ are used to estimate the position of a representative natural turbidity current on the Shields diagram (Supplementary Table 1 and Methods). The flows had a transitionally rough boundary and the Shields parameter plots above the suspension threshold (Fig. 1). Similarly, the boundary layer was transitionally rough in the present experiments and shear stresses were sufficiently high to support sustained suspension transport. As a result, these currents were sediment-bypass dominated along a significant part of the experimental domain. The experiments presented in this study were performed under Shields scaling conditions that are representative for the natural environment. Some previous confined slope experiments ${ }^{24,41}$ also plot in the natural turbidity current regime. The experiments presented here are, however, the first to satisfy both Froude and Shields scaling (Fig. 1) on an unconfined and erodible slope, making them suitable to study flow-substrate interactions during channel inception. 


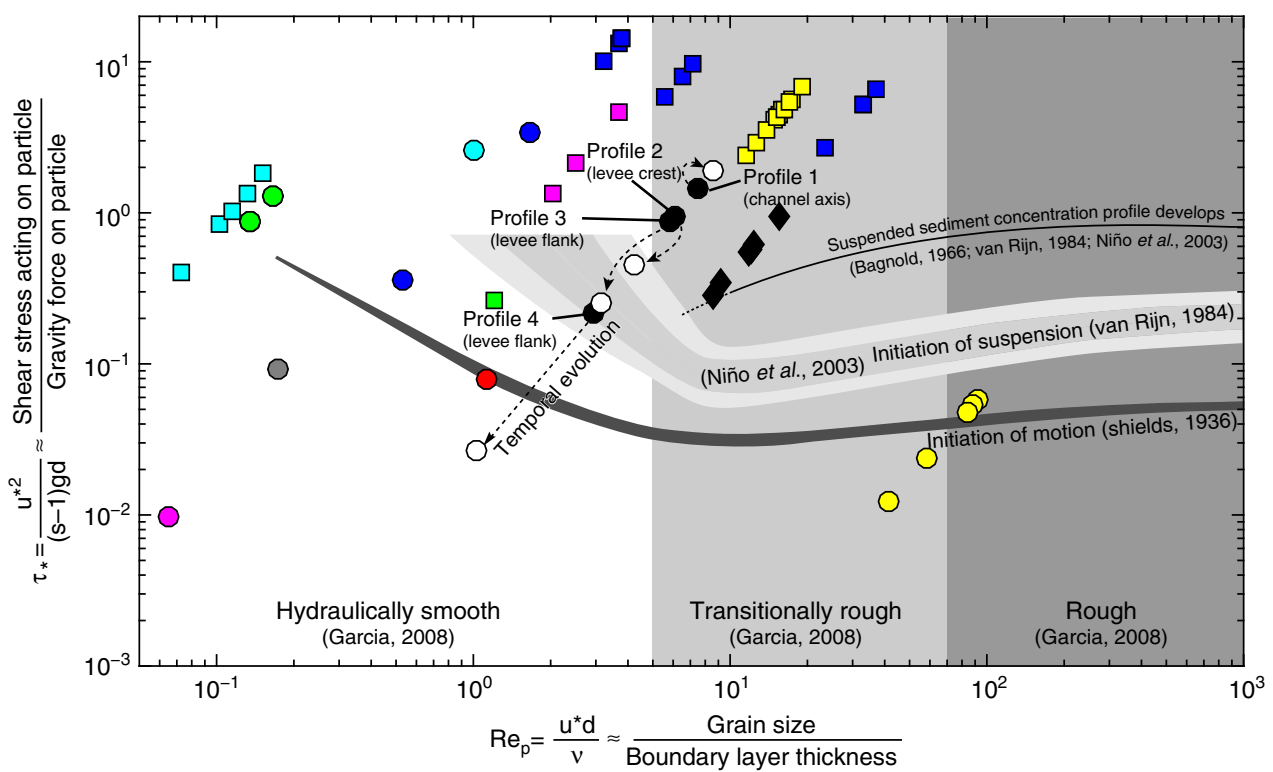

Experiments on unconfined
slope or shallow pre-fixed
channel (that is, confinement
depth< flow height)
Rowland et al., 2010
Mohrig and Buttles, 2007
Straub et al., 2008
Cantelli et al., 2011
Weill et al., 2014
Luthi, 1981
Kane et al., 2008

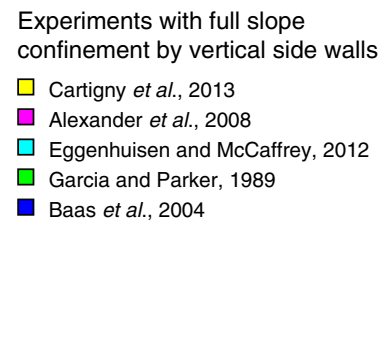

Present study (unconfined slope)

Present study (run 1) Present study (run 3) Natural turbidity currents Xu et al., 2010

Figure 1 | Regime diagram for sediment transport. Shields mobility diagram giving an overview of experimental conditions in previous studies $^{22-24,28-32,34,35,41,48}$, natural flows ${ }^{15}$ and the experiments presented in this study. Regime boundaries based on refs $38,40,49-51$.

It emerges that many previous studies violated the proposed Shields scaling requirements, because the flows had smooth boundary layers and/or had shear stresses that were below the threshold for initiation of suspension. In the cases where flows had a smooth boundary layer and low Shields parameter ${ }^{28,30,32,34}$, flows were always depositional. Flows in other experiments ${ }^{29,31,33}$ had a higher Shields parameter but still a smooth boundary layer. Finally, the experiments of Rowland et $a .^{23}$ fulfilled the roughness requirement; however, there the Shields parameter was only approximately equal to the critical value for initiation of bedload motion (Fig. 1). None of these experiments led to channelization morphodynamics.

Morphological evolution. Three turbidity currents with the same characteristics were released successively on a constant and initially featureless sand slope (boundary conditions in Table 1 and set-up shown in Supplementary Fig. 1). The first turbidity current deposited two sub-parallel ridges, while the flow largely bypassed in between the two ridges (Fig. 2). This pattern of deposition resulted in a morphology that confined the subsequent flows. The relief of this confinement was increased during the subsequent second and third run due to continued deposition on the ridges. A circular scour with a diameter of $70 \mathrm{~cm}$ and a final depth of $8 \mathrm{~cm}$ is created in between the levees on the upper slope domain throughout the three runs. This contributes to the channel relief in that reach. On the lower slope, erosion in between the ridges was only initiated during the second run. The ridges are built of layers deposited by successive turbidity currents that are thinning away from the channel axis and therefore the ridges can be qualified as levees ${ }^{42}$.
Table 1 | Boundary conditions of the experiments.

Input sediment concentration

Suspension discharge

Median grain size

Bed slope

$17 \%$ vol

$30 \mathrm{~m}^{3} \mathrm{~h}^{-1}$

$141 \mu \mathrm{m}$

$11^{\circ}$

The cross-sectional geometry of the experimental channel compares well with submarine channels on the modern seafloor that have remained unfilled. The depth:width ratio of the Lucia Chica channel (Fig. 3) is 1:12, whereas the aspect ratio formed in the experiment varies between 1:9 and 1:23.

The amount of sediment bypass on the slope increases in each run as is indicated by an increasing fraction of the sediment reaching the base of slope. The fraction of sediment that reaches the base of slope increases from $66 \%$ in run 1 to $80 \%$ in run 3 (Fig. 4).

Evolution of the flow field. The effect of the evolving topography on the flow field is shown by velocity profiles along a slope-perpendicular section (Fig. 5a and Supplementary Figs 2-4). At the beginning of run 1, when the slope was not yet modified, there was little across-flow variation in the downstream velocity profile. The confining morphology established by the end of run 1 resulted in an increase in flow velocity inside the confinement ( $U_{\max }$ increases from 0.83 to $1.00 \mathrm{~m} \mathrm{~s}^{-1}$ at velocity profile 1 ; height of $U_{\max }$ was $1.2 \mathrm{~cm}$ ) and a decrease in flow velocity outside of the confinement $\left(U_{\max }\right.$ decreases from 0.64 to $0.38 \mathrm{~m} \mathrm{~s}^{-1}$ at velocity profile 3 ). It is noteworthy that the 
a
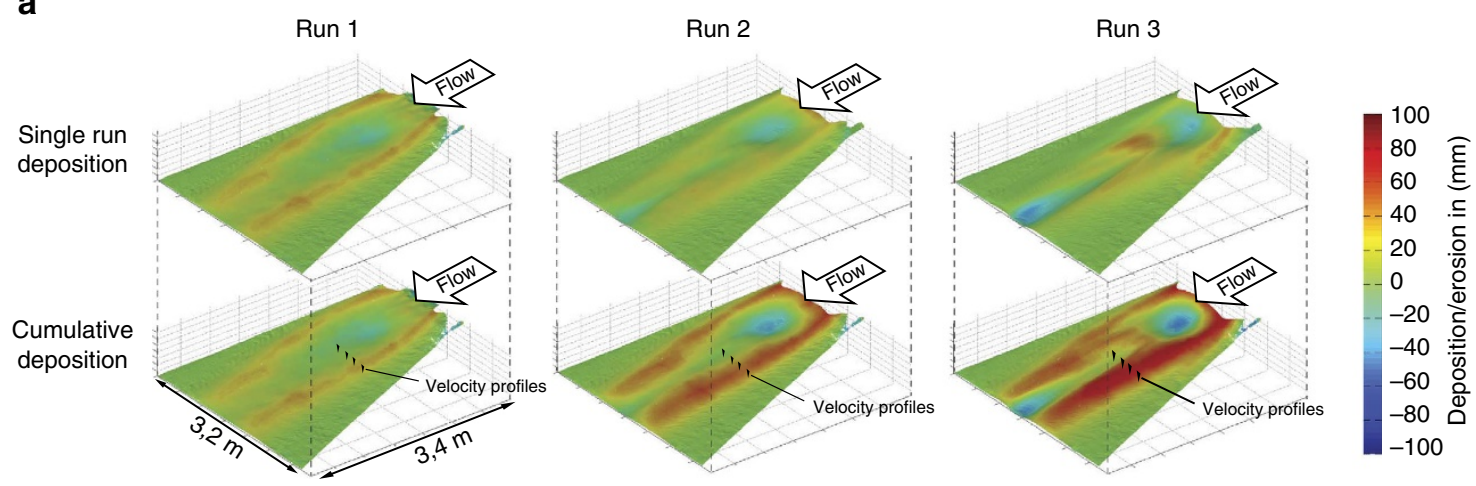

b

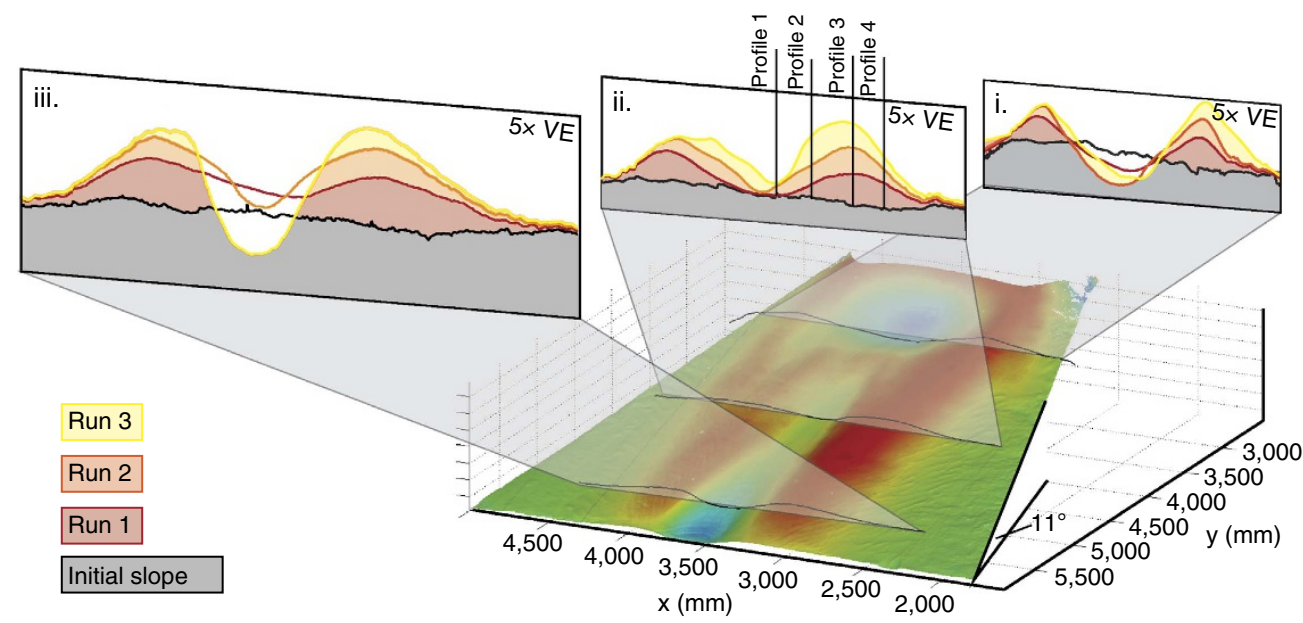

Figure 2 | Maps of deposition and erosion. (a) Digital elevation models of the deposits formed by sandy turbidity currents. Colours indicate the thickness of the deposits/depth of erosion. Both the cumulative erosion/deposition and the erosion/deposition after each single run are shown. (b) DEM of the final deposit with cross-sections at the lower, middle and upper slope. Cross-sections have five times vertical exaggeration. Positions of the probes that measured downstream velocity profiles are indicated on cross-section ii.
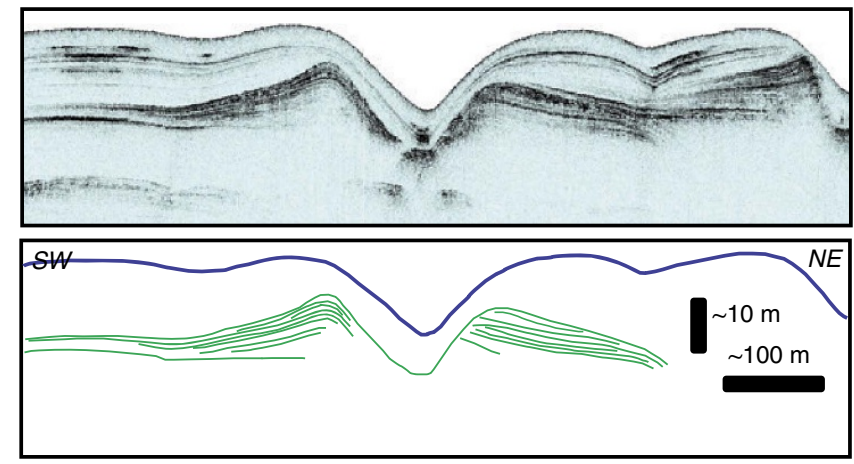

Figure 3 | Example of a submarine channel on the modern seafloor. Chirp profile through a submarine channel that is part of the Lucia Chica channel system offshore central California ${ }^{10}$. The green lines indicate the turbidity current deposits. Compare this figure with the cross-sections of the experimental deposits in Fig. 2b. The blue line indicates the top of the hemipelagic drape (figure reprinted with permission from the publisher).

change in the flow field during run 1 was caused by a channel with a depth $\left(h_{U \max }=2.6 \mathrm{~cm}\right)$ that was only a fraction of the flow height $(h=7.3 \mathrm{~cm})$. The increase in channel depth during runs 2 and 3 does not result in a systematic change in flow velocity at any of the profiling locations. These results confirm previous prefixed channel experiments ${ }^{28}$, which showed that a flow is already

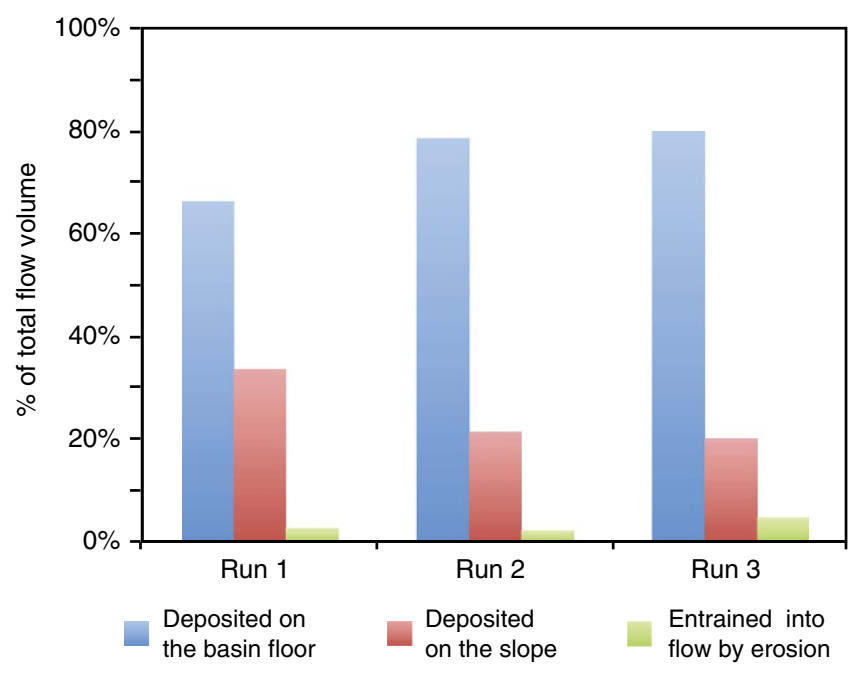

Figure 4 | Volume of deposits on the slope. Fractions of the total sediment load of the flow deposited and eroded on the slope and on the basin floor. The volume of sediment supplied to the experiments is equal for each of the runs.

effectively confined within a conduit once the channel depth is greater than the height of the velocity maximum.

The spatial and temporal variations in flow velocity affected the ability of the flows to transport their sediment and these changes 
a

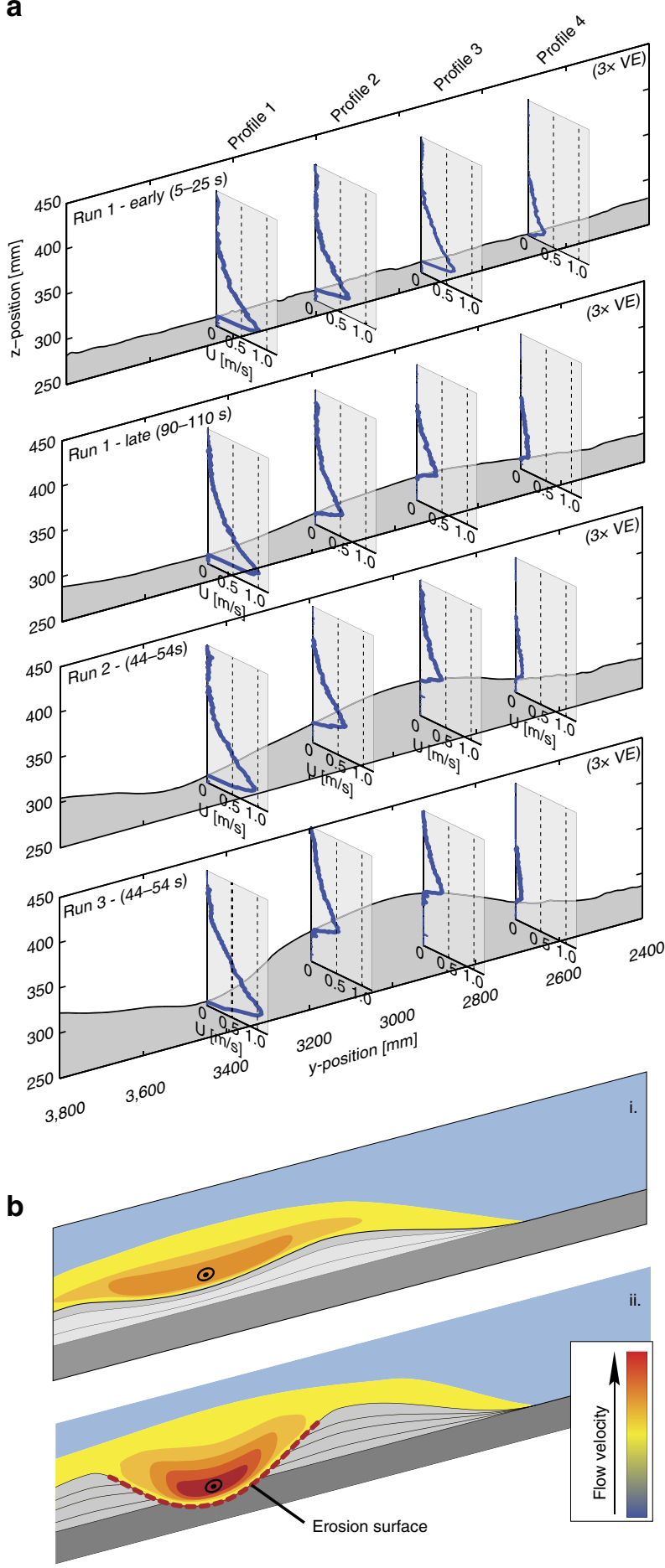

Figure 5 | Changes in flow velocity as a result of increasing confinement. (a) Topographic profiles with time-averaged velocity profiles measured along the same transect at different time intervals (early run 1 (5-25 s), late run 1 ( $90-110 \mathrm{~s}$ ), middle run 2 (44-54s) and middle run 3 (44-54s)). The full velocity time series are supplied in Supplementary Note 3 . It is noteworthy that there is three times vertical exaggeration in the topographic profiles. (b) Model for the co-evolution of the flow field and the topography derived from the experiments: (i) broad and weakly confined flows build a subtle depositional confinement, because deposition rates are slightly lower in the axis. (ii) A threshold at which incision start is reached, causing a rapid increase in the confinement relief. It is noteworthy that the erosion of the channel floor was only observed downstream of the location of velocity profile 1 . can be tracked within the Shields diagram (Fig. 1). The flow along the centreline of the slope (Fig. 5a, velocity profile 1) has a transitionally rough boundary layer and is able to bypass/erode sediment until the base of the slope. Flow at the off-axis locations of velocity profile 2 and 3 plot near the boundary between smooth and transitionally rough flow during run 1 . The position of these points shifts towards the hydraulically smooth regime and below the suspension initiation threshold during run 3 . Thus, the conditions at the locations of velocity profiles 2 and 3 are at or below the conditions for sediment bypass, and thus there is continuous deposition at these localities. The flow furthest away from the axis (Fig. 5a, velocity profile 4) plots within the field where flows have a smooth boundary layer and are below the boundary for suspended sediment transport during all runs. This indicates that flows that carry suspended load are highly depletive in these realms.

The temporal increase in axial flow velocity, which is caused by the progressively increasing confinement, causes an increase in the Shields parameter (Fig. 1, profile 1). The resulting small shift on the Shields diagram of the position of the flow at profile 1 appears to have little effect on the ability of the flow to transport sediment at this locality, because little deposition or erosion is observed here throughout the three runs. Although axial flow velocity was not monitored in the lower channel section, a larger shift on the Shields diagram can be inferred there because of the observed transition from deposition on the channel floor during run 1 to erosion on the channel floor during run 2 and 3 (Fig. $2 \mathrm{~b}$, cross-section iii.). The axial erosion is a further contributor to flow confinement in a dynamic feedback and consequently increases the rates of erosion.

In contrast, the flow conditions at the off-axis locations (velocity profiles 2, 3 and 4 ) are shifting in the Shields mobility diagram towards positions below the suspension initiation threshold and indeed there is continuous deposition at these localities.

In summary, spatial and temporal variation in the ability to transport sediment is predicted from the velocity measurements. The relative positions and temporal evolution on the Shields diagram predict the deposition of levees alongside a fairway dominated by sediment bypass and reflects progressive confinement increase during channel inception (Fig. 5b).

\section{Discussion}

Significant debate has surrounded the nature of the relief that is created during the initial phase of channel formation. It has been argued that initial relief that turbidity currents create at a site of repeated activity is likely erosional ${ }^{9,10}$, which implies that levees commonly form from overspill after formation of an entrenched channel confinement. Trains of erosional scours are widely observed on the floors of channels on the modern ocean floor ${ }^{3,4,9,42-44}$ and are indeed a probable initial feature of channelization in many cases. Similarly, the scour in front of the outlet in the present experiments contributes to the initial confinement on the upper slope. However, the initial confinement along the middle and lower slope is created purely by depositional patterns arising from low deposition rates below the flow axis compared with the flow margins. Thus, the incipient levees formed by lateral variations in sediment transport processes and not by overspill from an already established channel. This morphodynamic development confirms the role that depositional templates may play in initial confinement $8,11,12$, and the experimental deposit cross-sections are strongly reminiscent of classic observational suggestions of depositional channel architecture $^{7,45}$

Channel axis erosion caused by initial depositional confinement represents transition from depositional channelization to 
erosional channelization (Fig. 5b). This is a confirmation of a 'channelization threshold' at which a subtle confinement created by small depositional gradients causes incision, followed by a channelization feedback ${ }^{11}$. It emerges that channelization of turbidity currents can arise from both depositional and erosive sculpting of the seafloor, and may transition from depositional to erosive confinement. These flows thus have various intrinsic tendencies for channelization, which explains the ubiquitous presence of channels on submarine slopes.

The channel inception debate is just one of the many aspects of seafloor morphodynamics that can now be subjected to thorough testing in the laboratory environment. Previously, this was not possible, because experimental turbidity currents did not show realistic patterns of deposition and erosion as a result of inadequate scaling of the suspended sediment transport.

We conclude that confinement can progressively evolve from a depositional or erosional template, promoting gradual enhancement of sediment bypass on the slope. The increase in sediment bypass during the early phase of channel evolution will result in autogenic progradation of the system and deposits with according stacking patterns. Coarse-grained deposits can be expected at the base of finer-grained levees; such coupled stratigraphic bodies can be explained with a single genetic sequence of progressive channel inception, without the need to invoke changes in external mechanisms.

\section{Methods}

Description of the set-up. The experiments were conducted in the Eurotank Flume Laboratory at Utrecht University. The Eurotank measures $6 \times 11 \mathrm{~m}$ in planform and was filled with water up to a level of $1.2 \mathrm{~m}$ above the horizontal floor (Supplementary Fig. 1). The bathymetry at the bottom of the tank consisted of a slope of $11^{\circ}$ and a horizontal basin floor at the base of this slope. The slope was covered with a $10-\mathrm{cm}$-thick layer of loose sand that had the same grain-size distribution as the turbidity currents. A wooden duct was present at the top of the slope, to resemble a non-erodible canyon setting at the top of the slope. At the other end of the slope, a 10-cm-high ridge was placed, to provide down-dip accommodation for the sediment that reached the base of the slope

Sediment suspensions. Before each experiment, the sediment mixture was prepared outside the tank in a $1.1-\mathrm{m}^{3}$ mixing tank, with two propellers designed to homogenize sediment-water mixtures up to $30 \%$ volumetric sediment concentrations. The quartz sand used to make the suspensions had a median grain size $\left(D_{50}\right)$ of $141 \mu \mathrm{m}$, a $D_{10}$ of $44 \mu \mathrm{m}$ and a $D_{90}$ of $199 \mu \mathrm{m}$ (Supplementary Fig. 5), and had a specific density of $2,650 \mathrm{~kg} \mathrm{~m}^{-3}$. The grain size was analysed using a Malvern Mastersizer particle sizer.

Data collection. During the experiments, a slurry pump was used to supply the suspension to the set-up. A discharge meter (Krohne Optiflux 2300) was mounted in the supply pipe. The discharge was regulated by a Labview control system that adjusted the pump speed whenever the measured discharge deviated from a set reference value. The discharge during each of the experiments presented here was $30 \mathrm{~m}^{3} \mathrm{~h}^{-1}$. The experiments lasted $\sim 100 \mathrm{~s}$ before the mixing tank was drained. Four Ultrasonic Doppler Velocity Profiler probes (UVP Duo MX, $1 \mathrm{MHz}$ ) were installed on an aluminium frame, to monitor the flow field during the experiments. These probes were set up at around $0.15 \mathrm{~m}$ above the erodible basin floor, with their beam pointing diagonally down into the flow at an angle of $60^{\circ}$ relative to the initial local slope of the flume floor. The planview location of the probes is indicated in Fig. 2. Each of these probes measured a full profile of bed-parallel flow in the direction of the probe orientation. The profiles had a spatial resolution of $0.64 \mathrm{~mm}$ and the measurement frequency was $1.81 \mathrm{~Hz}$. Individual velocity profiles have a spiky appearance due to the turbulent nature of the flows. Therefore, timeaveraging was applied to create smoother profiles as presented in Fig. 5a. After each experimental run, the basin was drained to expose the deposit. Next, a digital elevation model (DEM) with a horizontal resolution of $2 \times 2 \mathrm{~mm}$ was created using a laser scanner. By subtracting the DEM of the experimental deposits and a DEM of the sediment bed before the experiments, a map of deposition and erosion was created for each experiment.

Determination of flow conditions. The following flow parameters were required to determine the position of each reviewed experiment on the Shields diagram (Fig. 1):
Grain size $(d)$ : Here, the median grain size of the initial sediment mixture was used.

Kinematic viscosity $(v)$ : Here, the viscosity of clear water at $20^{\circ}$ was used $\left(1 \times 10^{-6}\right)$

Shear velocity $\left(U^{\star}\right)$ : When estimates are supplied in experimental studies, then they are followed. Elsewise, the shear velocities were determined as ${ }^{46} U^{*}=\sqrt{g^{\prime} h S}$ For the present experiments, the shear velocity was determined using ${ }^{39}$ :

$$
U^{*}=U_{\max } \kappa\left[\ln \left(\frac{h_{\max }}{0.1 D_{90}}\right)\right]^{-1}
$$

where $h_{\max }$ is the height of the velocity maximum and $U_{\max }$ is the maximum velocity.

Reduced gravity $\left(g^{\prime}\right): g(\Delta \rho / \rho)$, where $\rho$ is the density of the suspension and $\Delta \rho$ is the excess density of the sediment submerged in the ambient fluid. To calculate the density of the suspension, it is assumed that the density of the sediment concentration is equal to the concentration of the initial mix.

Flow height up to the velocity maximum $(h)$ : If only the total flow thickness was given, it was assumed that the height of the velocity maximum is at one-fourth of the total flow thickness.

Bed slope $(S)$ : $\sin$ (bed slope in degrees).

Flow conditions for turbidity currents in the Monterey canyon were determined using information reported in ref. 15. A representative median grain size for the turbidity currents was estimated from sediment cores of the Monterey canyon floor. Core data in ref. 47 shows that a broad range of grain sizes (ranging from silt to boulders) were deposited on the canyon floor. Middle sand (diameter of $350 \mu \mathrm{m}$ ) was chosen as a representative grain size, because it was the most common grain size in the cores. The $D_{90}$ was estimated at $500 \mu \mathrm{m}$. The shear velocity was determined using the formula that is also used for this purpose for the present experiments.

\section{References}

1. Talling, P., Wynn, R., Masson, D. \& Frenz, M. Onset of submarine debris flow deposition far from original giant landslide. Nature 450, 541-544 (2007).

2. Damuth, J. E. et al. Meandering channels meandering and bifurcation patterns on the Amazon deep sea fan as revealed by pong-range side-scan sonar. Geology 11, 94-98 (1983).

3. Maier, K. L. et al. The elusive character of discontinuous deep-water channels: new insights from Lucia Chica channel system, offshore California. Geology 39, 327-330 (2011).

4. Hay, A. E. Turbidity currents and submarine channel formation in Rupert Inlet, British Columbia: 2. The roles of continuous and surge-type flow. J. Geophys. Res. Ocean 92, 2883-2900 (1987)

5. Stevenson, C. J., Jackson, C. A., Hodgson, D. M., Hubbard, S. M. \& Eggenhuisen, J. T. Deep-water sediment bypass. J. Sediment. Res. 85, 1058-1081 (2015).

6. Galy, V. et al. Efficient organic carbon burial in the Bengal fan sustained by the Himalayan erosional system. Nature 450, 407-410 (2007).

7. Clark, J. D. \& Pickering, K. T. Architectural elements and growth patterns of submarine channels: application to hydrocarbon exploration. Am. Assoc. Pet. Geol. Bull. 80, 194-221 (1996).

8. Morris, E. et al. Sedimentology, stratigraphic architecture, and depositional context of submarine frontal-lobe complexes. J. Sediment. Res. 84, 763-780 (2014).

9. Fildani, A. et al. Erosion at inception of deep-sea channels. Mar. Pet. Geol. 41, 48-61 (2013).

10. Maier, K. L. et al. Deep-sea channel evolution and stratigraphic architecture from inception to abandonment from high-resolution Autonomous Underwater Vehicle surveys offshore central California. Sedimentology 60, 935-960 (2013).

11. Eggenhuisen, J. T., McCaffrey, W. D., Haughton, P. D. W. \& Butler, R. W. H. Shallow erosion beneath turbidity currents and its impact on the architectural development of turbidite sheet systems. Sedimentology 58, 936-959 (2011).

12. Ortiz-Karpf, A., Hodgson, D. M. \& McCaffrey, W. D. The role of masstransport complexes in controlling channel avulsion and the subsequent sediment dispersal patterns on an active margin: the Magdalena Fan, offshore Colombia. Mar. Pet. Geol. 64, 58-75 (2015).

13. Sun, T., Ghayour, K., Hall, B. \& Miller, J. in Proceedings of the 30 th GCSSEPM Foundation Bob F Perkins Research Conference Houston, Texas, USA (2011).

14. Stevenson, C. J. et al. The flows that left no trace: very large-volume turbidity currents that bypassed sediment through submarine channels without eroding the sea floor. Mar. Pet. Geol. 41, 186-205 (2013).

15. $\mathrm{Xu}, \mathrm{J}$. P. Normalized velocity profiles of field-measured turbidity currents Geology 38, 563-566 (2010).

16. Xu, J. P., Noble, M. A. \& Rosenfeld, L. K. In-situ measurements of velocity structure within turbidity currents. Geophys. Res. Lett. 31, L09311 (2004).

17. Cooper, C., Wood, J. \& Andrieux, O. in Offshore Technology Conference 2012 Proceedings Houston, Texas, USA (2013).

18. Hughes Clarke, J. E., Brucker, S., Muggah, J., Church, I. \& Cartwright, D. The Squamish Delta Repetitive Survey Program: a simultaneous investigation of 
prodeltaic sedimentation and integrated system accuracy. U.S. Hydrographic Conference 1-16 (2011).

19. Hughes Clarke, J. E. et al. Monitoring the evolution of submarine channels on Fjord Prodeltas and associated depositional basins. AAPG Search Discov. 41678 (2015).

20. Metivier, F., Lajeunesse, E. \& Marie-Christine, C. Submarine Canyons in the bathtub. J. Sediment. Res. 75, 6-11 (2005).

21. Hoyal, D., Sheets, B. A., Edwards, C. M. \& Bloch, R. B. Controls from channel formation in deep water distributive systems. AAPG Search Discov. 50090 (2008).

22. Weill, P., Lajeunesse, E. \& Devauchelle, O. Experimental investigation on self-channelized erosive gravity currents. J. Sediment. Res. 84, 487-498 (2014).

23. Rowland, J. C., Hilley, G. E. \& Fildani, A. A test of initiation of submarine leveed channels by deposition alone. J. Sediment. Res. 80, 710-727 (2010).

24. Baas, J., Kesteren, W., Van \& Postma, G. Deposits of depletive high-density turbidity currents: a flume analogue of bed geometry, structure and texture. Sedimentology 51, 1053-1088 (2004).

25. Imran, J., Parker, G. \& Katopodes, N. A numerical model of channel inception on submarine fans. J. Geophys. Res. 103, 1219 (1998).

26. Yu, B. et al. Experiments on self-channelized subaqueous fans emplaced by turbidity currents and dilute mudflows. J. Sediment. Res. 76, 889-902 (2006).

27. Middleton, G. small-scale models of turbidity currents and the criterion for auto-suspension. J. Sediment. Petrol 36, 202-208 (1966).

28. Mohrig, D. \& Buttles, J. Deep turbidity currents in shallow channels. Geology 35, 155-158 (2007)

29. Straub, K. M., Mohrig, D., McElroy, B., Buttles, J. \& Pirmez, C. Interactions between turbidity currents and topography in aggrading sinuous submarine channels: a laboratory study. Geol. Soc. Am. Bull. 120, 368-385 (2008).

30. Cantelli, A., Pirmez, C., Johnson, S. \& Parker, G. Morphodynamic and stratigraphic evolution of self-channelized subaqueous fans emplaced by turbidity currents. J. Sediment. Res. 81, 233-247 (2011).

31. Luthi, S. Experiments on non-channelized turbidity currents and their deposits. Mar. Geol. 40, 59-68 (1981).

32. Kane, I. A., McCaffrey, W. D. \& Peakall, J. Controls on sinuosity evolution within submarine channels. Geology 36, 287-290 (2008).

33. Alexander, J. et al. Laboratory sustained turbidity currents form elongate ridges at channel mouths. Sedimentology 55, 845-868 (2008).

34. Eggenhuisen, J. T. \& McCaffrey, W. D. The vertical turbulence structure of experimental turbidity currents encountering basal obstructions: implications for vertical suspended sediment distribution in non-equilibrium currents. Sedimentology 59, 1101-1120 (2012).

35. Garcia, M. \& Parker, G. Experiments on hydraulic jumps in turbidity currents near a canyon-fan transition. Science 245, 393-396 (1989).

36. Peakall, J., Ashworth, P. \& Best, J. in The Scientific Nature of Geomorphology. (eds Rhoads, B. L. \& Thorn, C. E.) 221-253 (John Wiley and Sons, 1996).

37. Parsons, J. \& Garcia, M. Similarity of gravity current fronts. Phys. Fluids 10, 1-5 (1998).

38. Shields, A. Anwendung der Aehnlichkeitsmechanik und der Turbulenzforschung auf die Geschiebebewegung (Preussischen Versuchsanstalt für Wasserbau, 1936).

39. Rijn, L. C. Van. Principles of Sediment Transport in Rivers, Estuaries and Coastal Seas (Aqua Publications, 1993).

40. Garcia, M. Sedimentation Engineering: Processes, Measurements, Modeling and Practise (American Society of Civil Engineers, 2008).

41. Cartigny, M. J. B., Eggenhuisen, J. T., Hansen, E. W. M. \& Postma, G. Concentration-dependent flow stratification in experimental high-density turbidity currents and their relevance to turbidite facies models. J. Sediment Res. 83, 1046-1064 (2014)

42. Kane, I. A. \& Hodgson, D. M. Sedimentological criteria to differentiate submarine channel levee subenvironments: exhumed examples from the
Rosario Fm. (Upper Cretaceous) of Baja California, Mexico, and the Fort Brown Fm. (Permian), Karoo Basin, S. Africa. Mar. Petrol. Geol. 28, 807-823 (2011).

43. Heiniö, P. \& Davies, R. J. Trails of depressions and sediment waves along submarine channels on the continental margin of Espirito Santo Basin, Brazil. Geol. Soc. Am. Bull. 121, 698-711 (2009).

44. Covault, J. A., Kostic, S., Paull, C. K., Ryan, H. F. \& Fildani, A. Submarine channel initiation, filling and maintenance from sea-floor geomorphology and morphodynamic modelling of cyclic steps. Sedimentology 61, 1031-1054 (2014).

45. Mutti, E. \& Normark, W. R. in Deep Water Clastic Deposits: Models and Case Histories. (eds Legget, J. K. \& Zuffa, G. G.) 1-38 (Graham and Trotman, 1987).

46. Kneller, B. \& Mccaffrey, W. D. The interpretation of vertical sequences in turbidite beds: the influence of longitudinal flow. J. Sediment. Res. 73, 706-713 (2003).

47. Paull, C. K. et al. Origins of large crescent-shaped bedforms within the axial channel of Monterey Canyon, offshore California. Geosphere 6, 755-774 (2010).

48. Alexander, J. et al. Laboratory sustained turbidity currents form elongate ridges at channel mouths. Sedimentology 55, 845-868 (2007).

49. Bagnold, R. An approach to the sediment transport problem from general physics. U.S. Geol. Surv. Prof. Paper 422, I1-I37 (1966)

50. van Rijn, L. Sediment transport, part 2: Suspended load transport. J. Hydraul. Eng 110, 1613-1641 (1984).

51. Niño, Y., Lopez, F. \& Garcia, M. Threshold for particle entrainment into suspension. Sedimentology 50, 247-263 (2003).

\section{Acknowledgements}

This is a contribution of the Eurotank Studies of Experimental Deepwater Sedimentology (EuroSEDS), financially supported by the Dutch Organisation of Scientific Research (NWO), ExxonMobil, Shell and Statoil. Patrick Michielsen and Martijn ter Braack have assisted during the laboratory experiments.

\section{Author contributions}

M.J.B.C. and J.T.E. developed the scaling approach. J.d.L. conducted the experiments, analysed the results and wrote the initial manuscript. All authors edited the manuscript

\section{Additional information}

Supplementary Information accompanies this paper at http://www.nature.com/ naturecommunications

Competing financial interests: The authors declare no competing financial interests

Reprints and permission information is available online at http://npg.nature.com/ reprintsandpermissions/

How to cite this article: de Leeuw, J. et al. Morphodynamics of submarine channel inception revealed by new experimental approach. Nat. Commun. 7:10886 doi: $10.1038 /$ ncomms10886 (2016)

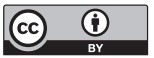

This work is licensed under a Creative Commons Attribution 4.0 International License. The images or other third party material in this article are included in the article's Creative Commons license, unless indicated otherwise in the credit line; if the material is not included under the Creative Commons license, users will need to obtain permission from the license holder to reproduce the material. To view a copy of this license, visit http://creativecommons.org/licenses/by/4.0/ 